\title{
Performance of cardiovascular risk scores in mortality prediction ten years after Acute Coronary Syndromes
}

DAmanda Aparecida Petek ${ }^{1}$

(i) Nara Aline Costa ${ }^{1}$

(iD) Filipe Welson Leal Pereira ${ }^{1}$

(iD) Ezequiel Aparecido dos Santos ${ }^{1}$

(iD) Katashi Okoshi ${ }^{1}$

(D) Silmeia Garcia Zanati ${ }^{1}$

(iD) Paula Schmidt Azevedo ${ }^{1}$

(iD) Bertha Furlan Polegato ${ }^{1}$

(D) Sergio Alberto Rupp de Paiva ${ }^{1}$

DLeonardo Antônio Mamede Zornoff'

(iD) Marcos Ferreira Minicucci ${ }^{1}$

1. Departamento de Clínica Médica, Faculdade de Medicina de Botucatu, Unesp - Univ Estadual Paulista, Botucatu, Brasil

\section{SUMMARY}

BACKGROUND: The objective of this study was to evaluate the performance of the Framingham risk score (FRS) and risk score by the American College of Cardiology/American Heart Association (SR ACC/AHA) in predicting mortality of patients ten years after acute coronary syndrome (ACS).

METHODS: This is a retrospective cohort study that included patients aged $\geq 18$ years with ACS who were hospitalized at the Coronary Intensive Care Unit (ICU) of the Botucatu Medical School Hospital from January 2005 to December of 2006.

RESULTS: A total of 447 patients were evaluated. Of these, 118 were excluded because the mortality in 10 years was not obtained. Thus, 329 patients aged $62.9 \pm 13.0$ years were studied. Among them, $58.4 \%$ were men, and $44.4 \%$ died within ten years of hospitalization. The median FRS was 16 (14-18) \%, and the ACC/AHA RS was 18.5 (9.1-31.6). Patients who died had higher values of both scores. However, when we classified patients at high cardiovascular risk, only the ACC/AHA RS was associated with mortality $(p<0.001)$. In the logistic regression analysis, both scores were associated with mortality at ten years $(p<0.001)$.

CONCLUSIONS: Both FRS and SR ACC/AHA were associated with mortality. However, for patients classified as high risk, only the ACC/ AHA RS was associated with mortality within ten years.

KEYWORDS: Risk Assessment. Myocardial infarction. Angina, Unstable. Mortality.

\section{INTRODUCTION}

The ischemic heart diseases are the most common causes of death worldwide. ${ }^{1}$ Among them are the acute coronary syndromes (ACS), which can be divided into myocardial infarction with ST-seg-

DATE OF SUBMISSION: 14-May-2019

DATE OF ACCEPTANCE: 18-May-2019

CORRESPONDING AUTHOR: Nara Aline Costa,

Departamento de Clínica Médica, Faculdade de Medicina de Botucatu, Unesp. Rubião Júnior s/n, Botucatu, SP, Brasil CEP: 18618-970Phone: +55 (014) 38222969, Fax: +55 (014) 38222238

E-mail:na.costa@unesp.br 
ment elevation and non-ST-segment elevation ACS. Despite the reduction tendency of mortality rates, ischemic heart diseases account for more than 1.8 million deaths every year, approximately $20 \%$ of all deaths in Europe. ${ }^{1-4}$

Thus, the identification of patients at risk of developing of coronary artery disease is crucial. The goal of the strategy of screening asymptomatic individuals is to have a more aggressive treatment and, consequently, a reduction of ischemic events and cardiovascular mortality. Among these scores are the Framingham risk score (FRS) and the score proposed by the American College of Cardiology and the American Heart Association (ACC/AHA RS). ${ }^{5-7}$

Over the last two decades, risk scores have gone through significant changes in order to concentrate on the overall absolute risk as an important key for the assessment of individual risk. In addition, more recent studies seek to improve the performance of the scores already used with the introduction of serum markers of inflammation, heart failure, and myocardial injury. Until the present time, however, risk scores have been developed and validated almost exclusively in developed countries.

In addition, the scores have been built, in their majority, in populations with apparently no cardiovascular disease, so their conclusions relate to primary prevention and do not apply to patients with diagnosed coronary disease. For patients post ACS, some instruments of risk stratification have been developed, such as the Grace, Pursuit, and Timi scores. ${ }^{8-10}$ However, these scores assess intra-hospital mortality or, at most, the mortality after six months of an acute coronary event. Thus, instruments that assess the long-term mortality, such as the Framingham RS and the ACC/AHA RS, have still not been validated for patients with a prior coronary event.

In view of these aspects, the objective of this study was to evaluate the performance of the Framingham RS and the ACC/AHA RS in predicting mortality in patients ten years after an ACS.

\section{METHODS}

The present study was approved by the Ethics Committee of our institution, under the protocol (61090116.1.0000.5411). The Informed Consent Form (ICF) was waived in cases which death was identified in the medical or administrative records of the hospital.
The present work is an observational retrospective cohort study that included patients aged $\geq 18$ years, with ACS, who were admitted to the Coronary Intensive Care Unit (ICU) of the Hospital das Clínicas de Botucatu - UNESP, in the period from January 2005 to December 2006, and who had the exams for the calculation of cardiovascular risk scores. We excluded patients whose final outcome after ten years was not obtained or those who refused to participate in the study.

For the calculation of the sample size, we used the Fisher and Belle formula, with the following variables: mortality ten years after AMI of 30\% to 40\%, confidence interval of $95 \%$, and a sampling error of $5 \%$. The result was a minimum of 323 patients.

The clinical and demographic data and laboratory examinations were collected upon admission to the Coronary Care Unit. The systolic blood pressure, blood glucose, lipid profile used were those of the first measurement taken at the time of admission. The FRS and the ACC/AHA RS were calculated and the overall mortality after ten years of ACS was recorded. ${ }^{5-7}$

In relation to acute coronary syndromes, they were classified as AMI with ST-segment elevation and non-ST-segment elevation ACS (AMI with no ST elevation and unstable angina). The diagnosis of the ACS was performed according to the guidelines by the American Heart Association. ${ }^{11.12}$

Systemic arterial hypertension (SAH) and the presence of diabetes mellitus (DM) were defined according to previous studies ${ }^{13.14}$. Smoking was regarded as the current use of tobacco.

\section{Laboratory evaluation}

For the measurement of sodium, potassium, urea, creatinine, CT, HDL, creatine phosphokinase (CPK) and creatine phosphokinase-MB (CKMB), we used the dry chemical method (Ortho-Clinical Diagnostics Vitros 950®, Johnson \& Johnson). CPK and CKMB were dosed every six hours after admission and the highest value was recorded.

\section{Framingham risk score (FRS)}

We calculated the Framingham risk score. Patients were considered at high cardiovascular risk when they presented a risk of death greater than $20 \%$. For the calculation of risk, patients younger than 20 years old or older than 80 were classified into the youngest and oldest categories of age, respectively. ${ }^{5.6}$ 
Risk score proposed by the American College of Cardiology and the American Heart Association (ACC/AHA)

We calculated the risk score proposed by the ACC/AHA. Patients were considered at high risk for atherosclerotic cardiovascular disease when they had a percentage greater than or equal to $7.5 \%$. For the calculation of risk, patients younger than 40 years old or older than 80 were classified into the youngest and oldest categories of age, respectively. ${ }^{7}$

\section{STATISTICAL ANALYSIS}

The data were presented as mean and standard deviation or median and percentiles of $25 \%$ and $75 \%$. The categorical variables were analyzed using the $\chi^{2}$ test or Fisher's exact test. Continuous variables were analyzed by Student's t-test when they presented normal distribution and by the Mann-Whitney test for non-normal distribution. For the evaluation of score performance in relation to mortality, we used the ROC curve. We also used uni- and multivariate logistic regression analyses, adjusted for the variables, which were different in the univariate analysis, except for variables that were already included in the scores and those with multicollinearity. The level of significance was $5 \%$.

\section{RESULTS}

We evaluated 447 patients with ACS admitted to the coronary ICU. Of these, 118 were excluded since their mortality ten years after admission to the ICU was not obtained. Thus, 329 patients with an average age of $62.9 \pm 13.0$ years were studied. Out of that total, $58.4 \%$ were men, and $44.4 \%$ died within ten years after hospitalization. Of these, 63\% presented non-ST-segment elevation ACS, while $37 \%$ had AMI with ST-segment elevation. After comparing these two groups of ACS, mortality was similar $(\mathrm{p}=0.97)$.

The median of the FRS was 16 (14-18\%), with 17\% of the patients classified at high cardiovascular risk. In relation to the ACC/AHA RS, the median was 18.5 (9.1-31.6\%), with $79 \%$ of the patients classified at high cardiovascular risk, according to this score.

The demographic, clinical, and laboratory data of the patients evaluated and their relationship with tenyear mortality are presented in Table 1 . The patients who died were older and had higher values of creat-
TABLE 1. DEMOGRAPHIC AND CLINICAL DATA AND LABORATORY CHARACTERISTICS OF 329 PATIENTS WITH ACUTE CORONARY SYNDROME.

\begin{tabular}{|c|c|c|c|}
\hline \multirow[t]{2}{*}{ Variables } & \multicolumn{2}{|c|}{ Death within 10 years } & \multirow[t]{2}{*}{ P-value } \\
\hline & No $(n=183)$ & Yes $(n=146)$ & \\
\hline Age, years & $57.9 \pm 11.4$ & $69.2 \pm 12.1$ & $<0.001$ \\
\hline Male, No. (\%) & $108(59.0)$ & $84(57.5)$ & 0.87 \\
\hline SAH, No. (\%) & $138(75.4)$ & $116(79.5)$ & 0.46 \\
\hline DM, No. (\%) & $64(35.0)$ & $56(38.4)$ & 0.60 \\
\hline Smoking, No. (\%) & $73(39.9)$ & $63(43.2)$ & 0.63 \\
\hline $\mathrm{SBP}, \mathrm{mmHg}$ & $130(120-150)$ & $130(115-150)$ & 0.99 \\
\hline $\mathrm{TC}, \mathrm{mg} / \mathrm{dL}$ & $181(154-218)$ & $169(143-208)$ & 0.04 \\
\hline $\mathrm{HDL}, \mathrm{mg} / \mathrm{dL}$ & $36(30-46)$ & $36(30-47)$ & 0.96 \\
\hline CPK, U/L & 207 (93-1075) & $222(87-984)$ & 0.72 \\
\hline CKMB, U/L & $23(11-135)$ & $36(14-115)$ & 0.14 \\
\hline Creatinine, $\mathrm{mg} / \mathrm{dL}$ & $0.9(0.8-1.11)$ & $1.2(0.9-1.5)$ & $<0.001$ \\
\hline Ureia, mg/dL & $34.0(26.5-41.8)$ & $43.0(34.0-55.0)$ & $<0.001$ \\
\hline Sodium, mmol/L & $138(137-141)$ & $139(136-141)$ & 0.93 \\
\hline Potassium, mmol/L & $4.1(3.8-4.5)$ & $4.3(3.9-4.7)$ & 0.02 \\
\hline
\end{tabular}

TABLE 2. CARDIOVASCULAR RISK SCORES OF 329 PATIENTS WITH ACUTE CORONARY SYNDROME.

\begin{tabular}{l|l|l|l} 
Variables & \multicolumn{2}{l|}{ Death within 10 years } & P-value \\
\hline & No $(n=183)$ & Yes $(146)$ & \\
\hline FRS, \% & $15(13-17)$ & $17(14-18)$ & $<0.001$ \\
\hline FRS $>20 \%$ & $26(14.2)$ & $30(20.5)$ & 0.17 \\
\hline ACC/AHA RS, \% & $14.1(6.2-26.1)$ & $23.7(15.0-40.1)$ & $<0.001$ \\
\hline ACC/AHA RS $\geq 7,5 \%$ & $125(68.3)$ & $136(93.2)$ & $<0.001$ \\
\hline
\end{tabular}

FRS: Framingham risk score; AHA RS: risk score proposed by the ACC/AHA. Data in percentages and median ( $25 \%$ and $75 \%$ percentiles).

inine, urea, and potassium, and lower values of total cholesterol upon admission to the coronary ICU.

Furthermore, we found that the patients who progressed to death had higher scores, both on the FRS and the ACC/AHA RS. However, when we classified only patients with high cardiovascular risk, only the ACC/AHA RS was associated with mortality (Table 2). The area under the curve (AUC) of the association between the FRS and ten-year mortality in patients who had ACS was 0.6307, with 95\% CI 0.5708-0.6905 and $\mathrm{p}<0.001$. The cut-off point of the score that is associated with the highest mortality is over $14.3 \%$. With the cut-off point of $14.3 \%$, sensitivity was $74.66 \%$, specificity $42.62 \%$, positive predictive $50.93 \%$, and negative predictive value $67.83 \%$ (Figure 1).

The area under the curve (AUC) of the association between the ACC/AHA RS and ten-year mortality 
in patients who had ACS was 0.7015, with 95\% CI $0.6455-0.7576$ and $p<0.001$. The cut-off point of the score that is associated with the highest mortality is over $23.56 \%$. With the cut-off point of $23.56 \%$, sensitivity was $50.00 \%$, specificity $71.04 \%$, positive predictive $57.94 \%$, and negative predictive value $64.04 \%$ (Figure 1).

There was an association between the FRS and the overall mortality after ten years in the univariate logistic regression (OR: 1.115; IC95\%: 1.052-1.181; $\mathrm{p}<0.001)$ and in the multivariate analysis adjusted for creatinine and potassium (OR: 1.127; IC95\%: 1.056-1.204, $\mathrm{p}<0.001)$. There was also an association between the ACC/AHA RS and the overall mortality after ten years in the univariate logistic regression (OR: 1.047; IC95\%: 1.030-1.064; $\mathrm{p}<0.001$ ) and in the multivariate analysis adjusted for creatinine and potassium (OR: 1.043; IC95\%: 1.025-1.060, p<0.001).

\section{DISCUSSION}

The objective of this study was to evaluate the performance of two known risk scores for cardiovascular events in predicting mortality during the period of ten years in post-ACS patients. Our results show that both the FRS and the ACC/AHA RS were associated with mortality after ten years, with better performance by the ACC/AHA RS. In addition, for patients classified at high risk, only the ACC/AHA $\mathrm{RS}$ was associated with mortality after ten years.

The first aspect to be considered refers to the fact that, even though hospital mortality is relatively low in ACS, the same concept does not apply for longer periods of observation. Thus, in a period between one and ten years, patients with ACS present a mortality rate of around $10 \%$ and $45 \%$, respectively. ${ }^{1.15} \mathrm{In}$ our study, the mortality after ten years of follow-up was $44 \%$. Our data are in line with those found in the literature, but they also show that, despite the advances introduced in the treatment of these patients, the long-term prognosis remains poor.

It is also important to note that there was no difference in mortality after ten years among the patients who had ACS with and without ST-segment elevation, and the same is true $\mathrm{n}$ in relation to the $\mathrm{CPK}$ and $\mathrm{CKMB}$ markers of myocardial injury. This fact is in agreement with studies that show that, in the long term, there is no difference in mortality between patients who had ACS with or without ST-segment elevation. ${ }^{1-3}$

Another relevant aspect to be observed is that considering that approximately half of the patients with ACS will die in a period of ten years, the risk stratification of these patients becomes a priority. In this sense, the identification of patients at higher risk of unfavorable outcomes after the acute episode would
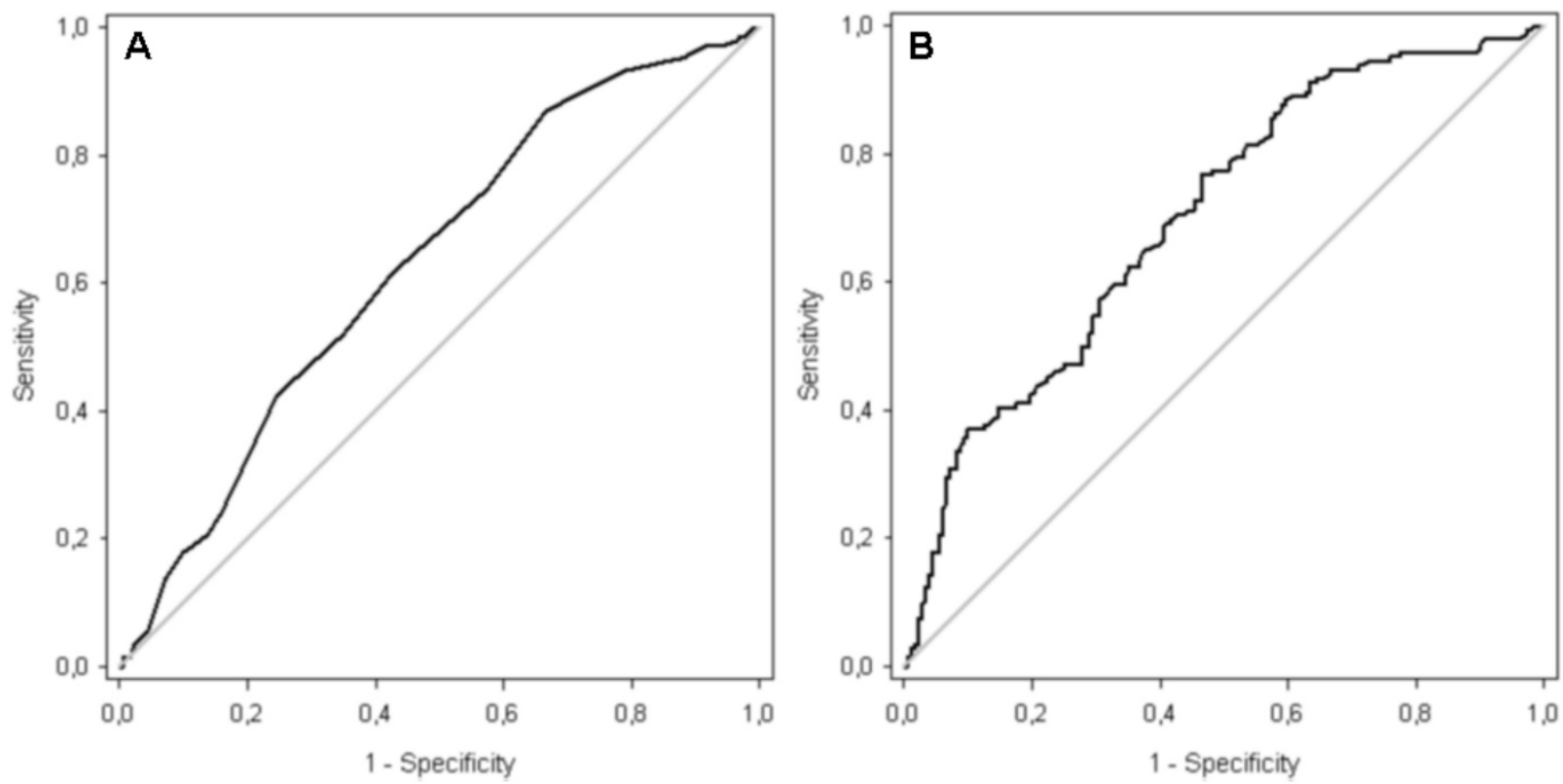

FIGURE 1 A. ROC CURVE OF THE ASSOCIATION BETWEEN THE FRAMINGHAM RISK SCORE AND TEN-YEAR MORTALITY AFTER ACUTE CORONARY SYNDROME. B. ROC CURVE OF THE ASSOCIATION BETWEEN THE RISK SCORE PROPOSED BY THE ACC/AHA AND TEN-YEAR MORTALITY AFTER ACUTE CORONARY SYNDROME 
allow for an individualized and more aggressive approach in these cases, improving the prognosis.

Taking into account the factors associated with ten-year outcomes, in our study, in addition to advanced age, higher values of the markers of renal function and potassium were also associated with greater mortality. This result is important because creatinine and potassium are not considered in most risk scores for coronary patients. ${ }^{16-18}$ In addition, there is an association between the decrease in renal function, associated or not to hyperkalemia, with increased risk of cardiovascular events. ${ }^{19.20}$

The Framingham and ACC/AHA scores are well-established and used for risk stratification of asymptomatic individuals. ${ }^{21-25}$ It is important to emphasize that our study was the first to assess and compare these scores in a population that has already presented coronary events. Furthermore, the use of these scores, even in a population that is mostly treated from a perspective of controlling risk factors and comorbidities, allows for the identification of patients who would benefit from more aggressive treatment. Another interesting point is that these scores are quick to be calculated and use laboratory examinations that are cheap and already part of the routine evaluation of patients with ACS.

In our study, both the FRS and the ACC/AHA
RS were associated with mortality in ten years. Additionally, the ACC/AHA RS had a better performance, despite discreet. Another important finding was that for patients classified at high risk, only the ACC/AHA RS was associated with mortality after ten years. Our results as a whole suggest that, specifically for patients with ACS, the ACC/AHA RS may be a better tool than the FRS for risk stratification in this scenario.

Finally, our study must be interpreted considering some limitations. This is a retrospective study, which included patients from a single center. Furthermore, the number of patients without information related to mortality after ten years was high. However, despite these restrictions, we believe that our data provide important information about the use of scores for risk stratification, in the long term, for patients with ACS.

\section{CONCLUSION}

Our data indicate that both the FRS and the ACC/ AHA RS were associated with mortality after ten years, with better performance by the ACC/AHA RS. In addition, for patients classified at high risk, only the ACC/AHA RS was associated with mortality after ten years.

\section{RESUMO}

OBJETIVO: Avaliar a performance do escore de risco de Framingham (ERF) e do escore proposto pela American College of Cardiology/ American Heart Association (ER ACC/AHA) em predizer a mortalidade em pacientes dez anos após síndrome coronariana aguda (SCA).

MÉTODOS: Trata-se de um estudo de coorte retrospectivo que incluiu pacientes com idade $\geq 18$ anos, com SCA, que estiveram internados na Unidade de Terapia Intensiva Coronariana (UTI) do Hospital das Clínicas de Botucatu, no período de janeiro de 2005 a dezembro de 2006 .

RESULTADOS: Foram avaliados 447 pacientes. Destes, 118 foram excluídos, pois a mortalidade em dez anos não foi obtida. Logo, 329 pacientes com idade de 62,9 $\pm 73,0$ anos foram estudados. Dentre eles, 58,4\% eram homens e 44,4\% morreram no período de dez anos após a internação. A mediana do ERF foi de 16 (14-18)\%, e do ER ACC/AHA foi 18,5 (9,1-31,6)\%. Os pacientes que evoluíram a óbito apresentaram maiores valores dos escores. No entanto, quando classificamos os pacientes em alto risco cardiovascular, apenas o ER ACC/AHA foi associado com a mortalidade $(p<0,001)$. Na análise de regressão logística, ambos os escores foram associados com a mortalidade em dez anos ( $p<0,001)$.

CONCLUSÕES: Tanto o ERF quanto o ER ACC/AHA foram associados com a mortalidade. No entanto, para os pacientes classificados como alto risco, apenas o ER ACC/AHA foi associado com a mortalidade em dez anos.

PALAVRAS-CHAVE: Medição de risco. Infarto do miocárdio. Angina instável. Mortalidade.

\section{REFERENCES}

1. Ibanez B, James S, Agewall S, Antunes M|, Bucciarelli-Ducci C, Bueno H, et al. 2017 ESC Guidelines for the management of acute myocardial infarction in patients presenting with ST-segment elevation: the Task Force for the management of acute myocardial infarction in patients presenting with
ST-segment elevation of the European Society of Cardiology (ESC). Eur Heart J. 2018;39(2):119-77.

2. Sugiyama T, Hasegawa K, Kobayashi Y, Takahashi O, Fukui T, Tsugawa Y. Differential time trends of outcomes and costs of care for acute myocardial 
infarction hospitalizations by ST elevation and type of intervention in the United States, 2001-2011. J Am Heart Assoc. 2015;4(3):e001445.

3. Townsend N, Wilson L, Bhatnagar P, Wickramasinghe K, Rayner M, Nichols M. Cardiovascular disease in Europe: epidemiological update 2016. Eur Heart J. 2016;37(42):3232-45.

4. Roffi M, Patrono C, Collet IP, Mueller C, Valgimigli M, Andreotti F, et al. 2015 ESC Guidelines for the management of acute coronary syndromes in patients presenting without persistent ST-segment elevation: Task Force for the Management of Acute Coronary Syndromes in Patients Presenting without Persistent ST-Segment Elevation of the European Society of Cardiology (ESC). Eur Heart J. 2016;37(3):267-315.

5. Dawber TR, Meadors GF, Moore Jr FE. Epidemiological approaches to heart disease: the Framingham Study. Am | Public Health Nations Health. 1951;41(3):279-81.

6. National Cholesterol Education Program (NCEP) Expert Panel on Detec tion, Evaluation, and Treatment of High Blood Cholesterol in Adults (Adult Treatment Panel III). Third Report of the National Cholesterol Education Program (NCEP) Expert Panel on Detection, Evaluation, and Treatment of High Blood Cholesterol in Adults (Adult Treatment Panel III) final report. Circulation. 2002;106(25):3143-421.

7. Stone NJ, Robinson JG, Lichtenstein AH, Bairey Merz CN, Blum CB, Ecke $\mathrm{RH}$, et al. $2013 \mathrm{ACC} / \mathrm{AHA}$ guideline on the treatment of blood cholesterol to reduce atherosclerotic cardiovascular risk in adults: a report of the American College of Cardiology/American Heart Association Task Force on Practice Guidelines. Circulation. 2014;129(25 Suppl 2):S1-45.

8. Granger CB, Goldberg RJ, Dabbous O, Pieper KS, Eagle KA, Cannon CP, et al. Predictors of hospital mortality in the global registry of acute coronary events. Arch Intern Med. 2003;163(19):2345-53.

9. Boersma E, Pieper KS, Steyerberg EW, Wilcox RG, Chang WC, Lee KL, et al Predictors of outcome in patients with acute coronary syndromes withou persistent ST-segment elevation. Results from an international trial of 9461 patients. The PURSUIT Investigators. Circulation. 2000;101(22):2557-67.

10. Antman EM, Cohen M, Bernink PJ, McCabe CH, Horacek T, Papuchis $\mathrm{G}$, et al. The TIMI risk score for unstable angina/non-ST elevation MI: a method for prognostication and therapeutic decision making. JAMA. 2000;284(7):835-42

11. Antman EM, Anbe DT, Armstrong PW, Bates ER, Green LA, Hand M, et al. ACC/AHA guidelines for the management of patients with ST-elevation myocardial infarction; A report of the American College of Cardiology/ American Heart Association Task Force on Practice Guidelines (Committee to Revise the 1999 Guidelines for the Management of patients with acute myocardial infarction). J Am Coll Cardiol. 2004;44(3):E1-E211.

12. Braunwald E, Antman EM, Beasley IW, Califf RM, Cheitlin MD, Hochman JS, et al. ACC/AHA guideline update for the management of patients with unstable angina and non-ST-segment elevation myocardial infarction-2002: summary article: a report of the American College of Cardiology/
American Heart Association Task Force on Practice Guidelines (Committee on the Management of Patients With Unstable Angina). Circulation. 2002;106(14):1893-900.

13. Chobanian AV, Bakris GL, Black HR, Cushman WC, Green LA, Izzo |L |r, et al. Seventh Report of the loint National Committee on Prevention, Detection, Evaluation, and Treatment of High Blood Pressure. Hypertension. 2003;42(6):1206-52.

14. American Diabetes Association. Standards of medical care in diabetes. Diabetes Care. 2005;28:S4-36.

15. Plakht $Y$, Shiyovich $A$, Gilutz H. Predictors of long-term (10-year) mortality postmyocardial infarction: age-related differences. Soroka Acute Myocardial Infarction (SAMI) Project. J Cardiol. 2015;65(3):216-23.

16. Foley RN, Parfrey PS, Sarnak MJ. Epidemiology of cardiovascular disease in chronic renal disease. J Am Soc Nephrol. 1998;9(12 Suppl):S16-23.

17. Parfrey PS. Cardiac disease in dialysis patients: diagnosis, burden of disease, prognosis, risk factors and management. Nephrol Dial Transplant. 2000;15(Suppl 5):58-68

18. Levey AS, Beto |A, Coronado BE, Eknoyan G, Foley RN, Kasiske BL, et al. Controlling the epidemic of cardiovascular disease in chronic renal disease: what do we know? What do we need to learn? Where do we go from here? National Kidney Foundation Task Force on Cardiovascular Disease. Am Kidney Dis. 1998;32(5):853-906.

19. Beattie JN, Soman SS, Sandberg KR, Yee J, Borzak S, Garg M, et al. Determinants of mortality after myocardial infarction in patients with advanced renal dysfunction. Am | Kidney Dis. 2001;37(6):1191-200.

20. Dries DL, Exner DV, Domanski MI, Greenberg B, Stevenson LW. The prognostic implications of renal insufficiency in asymptomatic and symptomatic patients with left ventricular systolic dysfunction. | Am Coll Cardiol. 2000;35(3):681-9.

21. Magnoni M, Berteotti M, Norata GD, Limite LR, Peretto G, Cristell N, et al. Applicability of the 2013 ACC/AHA Risk Assessment and Cholesterol Treatment Guidelines in the real world: results from a multiethnic case-control study. Ann Med. 2016;48(4):282-92.

22. Ridker PM, Cook NR. Statins: new American guidelines for prevention of cardiovascular disease. Lancet. 2013;382(9907):1762-5.

23. Karmali KN, Goff DC Ir, Ning H, Lloyd-lones DM. A systematic examination of the 2013 ACC/AHA pooled cohort risk assessment tool for atherosclerotic cardiovascular disease. J Am Coll Cardiol. 2014;64(10):959-68.

24. Liu J, Hong Y, D'Agostino RB Sr, Wu Z, Wang W, Sun J, et al. Predictive value for the Chinese population of the Framingham CHD risk assessment tool compared with the Chinese Multi-Provincial Cohort Study. JAMA. 2004;291(21):2591-9.

25. Brindle P, Emberson I, Lampe F, Walker M, Whincup P, Fahey T, et al. Predictive accuracy of the Framingham coronary risk score in British men: prospective cohort study. BM|. 2003:327(7426):1267. 